\title{
ANALISIS KONSUMEN MEMILIH MINYAK MAKAN KEMASAN MENGGUNAKAN ANALYTICAL HIERARCHY PROCESS (AHP)
}

\author{
Consumer Analysis Of Selecting Packed Feding Oil Using \\ Analytical Hierarchy Process (Ahp) \\ Asbon Hendra Azhar ${ }^{1}$, Ratih Adinda Destari ${ }^{2}$ \\ Fakultas Teknik dan Ilmu Komputer, Universitas Potensi Utama \\ asbon.upu@gmail.com¹, adindaalkarim0384@gmail.com²
}

\begin{abstract}
Abstrak
Minyak makan merupakan salah satu produk yang dibutuhkan oleh Konsumen dalam memasak jenis makanan. Di kehidupan sehari-hari tidak semua minyak makan yang dipasarkan akan dibeli oleh konsumen, karena ada beberapa aspek atau kriteria yang sangat dibutuhkan oleh konsumen untuk membeli produk minyak makan. Apalagi sekarang sudah ada produk minyak makan yang diproduksi dalam kemasan, sehingga konsumen tidak perlu repot lagi membelinya dan bisa disimpan dengan baik dimanapun disimpan. Mengatasi permasalahan tersebut diperlukan suatu metode yang nantinya akan bisa mengambil suatu keputusan yang terbaik. Metode yang digunakan adalah metode Analitycal Hierarchy Process dimana merupakan salah satu metode yang mampu merepresentasikan tingkat kepentingan berbagai pihak dengan mempertimbangkan saling keterkaitan antar kriteria yang ada sehingga bisa menghasilkan hasil terbaik dalam memilih jenis minyak makan kemasan. Dalam penelitian ini didapat hasil skala prioritas yaitu untuk Minyak Makan Kemasan Bimoli dengan nilai 0.2949, Sunco nilai 0.253 , Kunci Mas nilai 0.2392 , dan Tropical nilai 0.2123. Dimana hasil ini nantinya bisa menjadi referensi bagi konsumen untuk memilih Produk Minyak Makan Kemasan yang terbaik.
\end{abstract}

Kata Kunci : AHP, Minyak Makan Kemasan, Konsumen

\begin{abstract}
Edible oil is one of the products needed by consumers in cooking types of food. In everyday life, not all edible oils that are marketed will be purchased by consumers, because there are several aspects or criteria that are urgently needed by consumers to buy edible oil products. Especially now that there are edible oil products that are produced in packaging, so consumers don't have to bother buying them anymore and can be stored properly wherever they are stored. Overcoming problems requires a method that will be able to take the best decision. The method used is the Analytical Hierarchy Process method which is one method that is able to represent the level of interest of various parties by considering the interrelationships between existing criteria so that it can produce the best results in choosing the type of packaged edible oil. In this study, the results obtained on a priority scale, namely for Bimoli Packaged Edible Oil with a value of 0.2949, Sunco a value of 0.253, Kunci Mas a value of 0.2392, and Tropical a value of 0.2123. Where these results can later be a reference for consumers to choose the best Packaged Eating Oil Products
\end{abstract}

Keywords: AHP, Oleofood Packaging, Consumer 


\section{PENDAHULUAN}

Produk minyak makan dalam kehidupan sehari-hari saat ini merupakan suatu kebutuhan yang sangat dibutuhkan oleh konsumen atau masyarakat. Jika konsumen salah dalam memilih minyak makan tentunya akan merugikan konsumen sendiri. Produk minyak makan pada saat ini selain ada dalam kemasan botol juga ada dalam kemasan plastik yang didesain dengan menarik sehingga konsumen jadi berminat untuk membelinya. Dalam memilih produk minyak makan yang terbaik dalam kemasan tersebut tentunya dibutuhkan beberapa kriteria maupun subkriteria yang ada agar mendapatkan hasil terbaik bagi konsumen yang membutuhkannya. Dari hal tersebut maka dibuatlah sebuah Sistem Pengambilan Keputusan, dimana dalam pengambilan keputusan tersebut digunakan software superdecision dengan menggunakan metode AHP. Dengan Penggunaan Metode AHP ini suatu persoalan yang kompleks pada suatu penelitian dapat disederhanakan dan prosesnya dapat dipercepat dalam pengambilan suatu keputusan (Faisal, et.al, 2012) [1].

\section{METODE PENELITIAN}

\subsection{Sistem Pendukung Keputusan}

SPK adalah sistem yang memberikan solusi untuk pemecahan masalah tertentu serta dirancang untuk pengambilan keputusan mulai dari mengidentifikasi masalah, memilih data yang relevan (Robby, et.al, 2015 Adhy, 2015))[2][3].

Sistem Pendukung Keputusan merupakan sebuah sistem yang dapat mendukung para pengambil keputusan manajerial dalam situasi keputusan semi terstruktur. Sistem pendukung keputusan dimaksudkan untuk menjadi alat bantu bagi para pengambil keputusan untuk memperluas kapabilitas mereka, namun bukan untuk menggantikan penilaian.

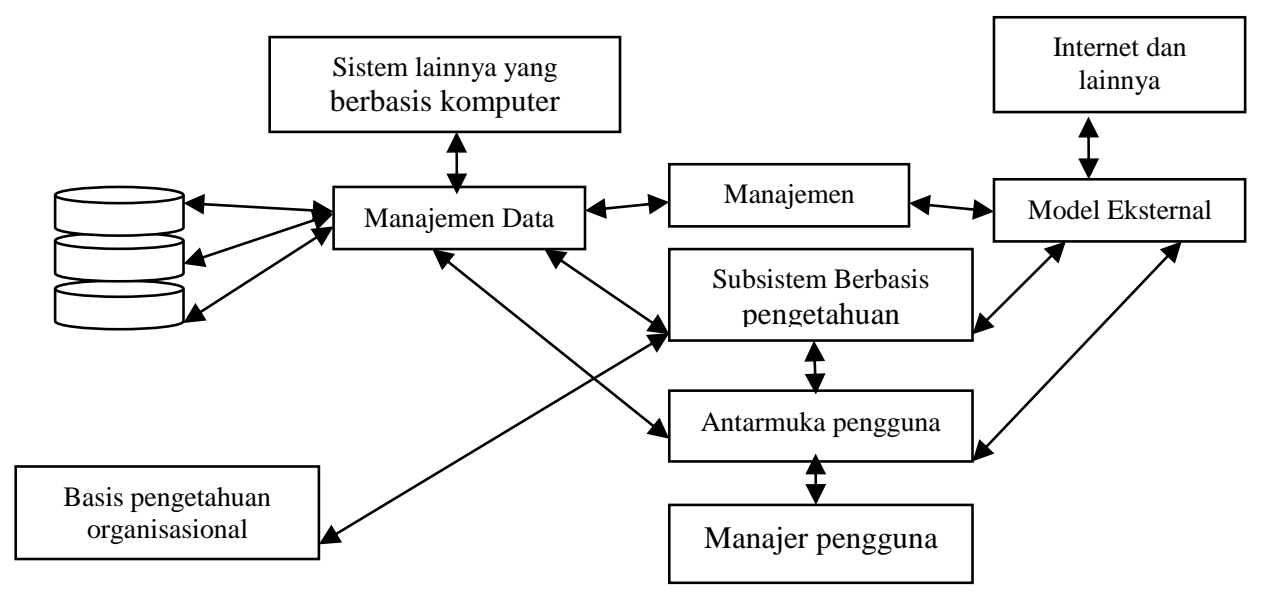

Gambar 1. Komponen SPK

Menurut Asep, et,al, 2012 dalam Dinda, 2016 [4], SPK punya karateristik yaitu :

1. Memberikan solusi dalam memecahkan masalah semi terstruktur ataupun tidak terstruktur.

2. Proses pengolahan dalam SPK kombinasi antara model-model analisis dengan data konvensional.

3. Dalam Perancangannya digunakan/dioperasikan sangat mudah.

4. Proses Perancangannya pada aspek fleksibilitas dan kemampuan tinggi. 


\subsection{Analytic Hierarchy Process (AHP)}

Menurut Zahedi,1997 dalam jurnal Sri, 2015 [5], Metode AHP mempunyai tujuan serta faktor subjektif dalam pengambilan keputusan. Metode ini bisa menentukan variabel tertinggi dan ditindaklanjuti untuk mendapatkan hasil keputusan. Adapun tahapannya yaitu:

1. Lakukan identifikasi masalah yang ada.

2. Tentukan kriteria-kriteria dan alaternatif-alternatif hingga level paling akhir.

3. Membuat matriks perbandingan berpasangan untuk setiap kriteria maupun alternatif yang ada skala dari angka-angka berapa kali lebih penting antara satu elemen dengan elemen yang lain berdasarkan kriteria yang ada.

4. Hitung bobot prioritas gunakan prioritas dari perbandingan pasangan yang ada untuk semua elemen.

5. Lakukan pengukuran rasio konsistensi dalam semua elemen yang ada yang untuk mengetahui apakah dilakukan revisi kembali matriks perbandingan berpasangan yang ada.

Perhitungan adalah :

$$
\begin{aligned}
& C I=\frac{\lambda \max -n}{n-1}, \\
& C R=C I / R C I
\end{aligned}
$$

keterangan :

CI = consistensi index

$N \quad=$ orde dari matriks

$\lambda \max =$ matriks ber-ordo $n$ terbesar dari nilai eigenvector

RI $=$ random index

6. Hasil dari rasio konsistensi harus $10 \%$ atau kurang. Seandainya lebih dari $10 \%$, maka akan diulang kembali pengukurannya hingga hasilnya harus $10 \%$ atau kurang.

\section{HASIL DAN PEMBAHASAN}

\subsection{Kebutuhan Data}

Dalam penelitian ini ada beberapa kondisi yang harus dibuat, dimana dalam menentukan suatu keputusan harus berhubungan dengan siapa yang akan memberikan keputusan. Dalam menentukan Hasil penetapan Memilih Minyak Makan Dalam Kemasan ini maka keputusan akan dinilai dari yang paling tinggi sehingga harus dilakukan adalah dengan membuat kriteria-kriteria dalam penelitian ini dimana dalam penelitian ini yang akan dipakai merupakan hasil penilaian terhadap kriteria yang ada.

Analisa datanya yaitu :

\subsubsection{Analisia Keterhubungan}

Dalam Analisia keterhubungan dalam penelitian ini langkah-langkahnya adalah sebagai berikut

a. Tujuan

Penelitian ini bertujuan Memilih Minyak Makan Kemasan Terbaik.

b. Kriteria

Penentuan kriteria yang digunakan adalah :

$>$ Harga

$>$ Bentuk Kemasan 
Pembelian

> Warna Minyak Makan

c. Alternatif

Penentuan Alternatif yang digunakan adalah :

1. Bimoli

2. Sunco

3. Kunci Mas

4. Tropical

\subsection{Pembuatan Kuesioner}

Pembuatan kuesioner dalam penelitian ini diajukan pada responden yang dibutuhkan dalam penelitian ini. Isi dari Kuesioner berupa pertanyaan perbandingan 2 node yang sudah dipilih didalam kluster kriteria serta antar kluster yang ada.

\subsubsection{Hasil Pembuatan Kuesioner}

Hasil rekapitulasi data kuesioner yang bisa dilihat ditabel 1 berdasarkan kriteria harga yang dihasilkan sedangkan pada tabel 2 berisikan Matriks Berpasangan Kriteria :

Tabel 1. Hasil Data Kuesioner

\begin{tabular}{|c|c|c|c|c|c|c|c|}
\hline No & Alternative 1 & Alternative 2 & A1 & A2 & A3 & A4 & A5 \\
\hline 1 & Bimoli & Tropical & 2 & -3 & -2 & -3 & -4 \\
\hline 2 & Bimoli & Sunco & -4 & 2 & -3 & -4 & -3 \\
\hline 3 & Bimoli & Kunci Mas & -6 & -4 & -3 & -2 & -5 \\
\hline 4 & Kunci Mas & Sunco & 6 & 2 & -6 & -2 & -2 \\
\hline 5 & Kunci Mas & Tropical & -5 & -3 & -2 & -3 & -2 \\
\hline 6 & Sunco & Tropical & -4 & -3 & -3 & -2 & 2 \\
\hline
\end{tabular}


Tabel 2. Matriks Berpasangan Kriteria

\begin{tabular}{|c|c|c|c|c|}
\hline Harga & Bimoli & Sunco & Kunci Mas & Tropical \\
\hline Bimoli & $\mathbf{1}$ & $\mathbf{1} / 2$ & $\mathbf{1 / 2}$ & $\mathbf{1} / \mathbf{4}$ \\
\hline Sunco & 2 & 1 & 2 & $1 / 2$ \\
\hline Kunci Mas & 2 & $1 / 2$ & 1 & $1 / 3$ \\
\hline Tropical & 4 & 2 & 3 & 1 \\
\hline
\end{tabular}

Untuk melakukan proses hasil bobot dalam kriteria harga ini maka dilakukan penjumlahan dalam setiap kolom yang ada dimana proses ini dapat dilakukan dengan menggunakan 4 digit dibelakang koma dan hasilnya bisa dilihat pada tabel 3 :

Tabel 3. Pembobotan dalam kriteria harga

\begin{tabular}{|c|c|c|c|c|c|c|}
\hline & Bimoli & Sunco & Kunci Mas & Tropical & Nilai Eigen & Bobot \\
\hline Bimoli & $\mathbf{1 . 0 0 0 0}$ & $\mathbf{0 . 5 0 0 0}$ & $\mathbf{0 . 5 0 0 0}$ & $\mathbf{0 . 2 5 0 0}$ & $\mathbf{0 . 2 9 4 9}$ & $\mathbf{3 0 \%}$ \\
\hline Sunco & $\mathbf{2 . 0 0 0 0}$ & $\mathbf{1 . 0 0 0 0}$ & $\mathbf{2 . 0 0 0 0}$ & $\mathbf{0 . 5 0 0 0}$ & $\mathbf{0 . 2 5 3 7}$ & $\mathbf{2 5 \%}$ \\
\hline Kunci Mas & $\mathbf{2 . 0 0 0 0}$ & $\mathbf{0 . 5 0 0 0}$ & $\mathbf{1 . 0 0 0 0}$ & $\mathbf{0 . 3 3 3 3}$ & $\mathbf{0 . 2 3 9 2}$ & $\mathbf{2 4 \%}$ \\
\hline Tropical & $\mathbf{4 . 0 0 0 0}$ & $\mathbf{2 . 0 0 0 0}$ & $\mathbf{3 . 0 0 0 0}$ & $\mathbf{1 . 0 0 0 0}$ & $\mathbf{0 . 2 1 2 3}$ & $\mathbf{2 1 \%}$ \\
\hline Jumlah & $\mathbf{9 . 0 0 0 0}$ & $\mathbf{4 . 0 0 0 0}$ & $\mathbf{6 . 5 0 0 0}$ & $\mathbf{2 . 0 8 3 3}$ & $\mathbf{1 . 0 0 0 0}$ & $\mathbf{1 0 0 \%}$ \\
\hline
\end{tabular}

Tabel diatas menunjukkan skala prioritas yang didapat dalam penelitian ini yaitu untuk Minyak Makan Kemasan Bimoli dengan nilai prioritas 0.2949 atau $30 \%$, Sunco nilai prioritas 0.2537 atau $25 \%$, Kunci Mas nilai prioritas 0.2392 atau 24\%, dan Tropical nilai prioritas 0.2123 atau $21 \%$.

\subsection{Pengujian Menggunakan Tools Superdecision.}

Dalam gambar 2 terlihat proses dalam Pengujian dimana langkah pertama adalah membuat cluster, kemudian langkah berikutnya membuat node di cluster lakukan dengan cara klik kanan cluster alternative kemudian diklik create node in cluster. node kemudian disimpan

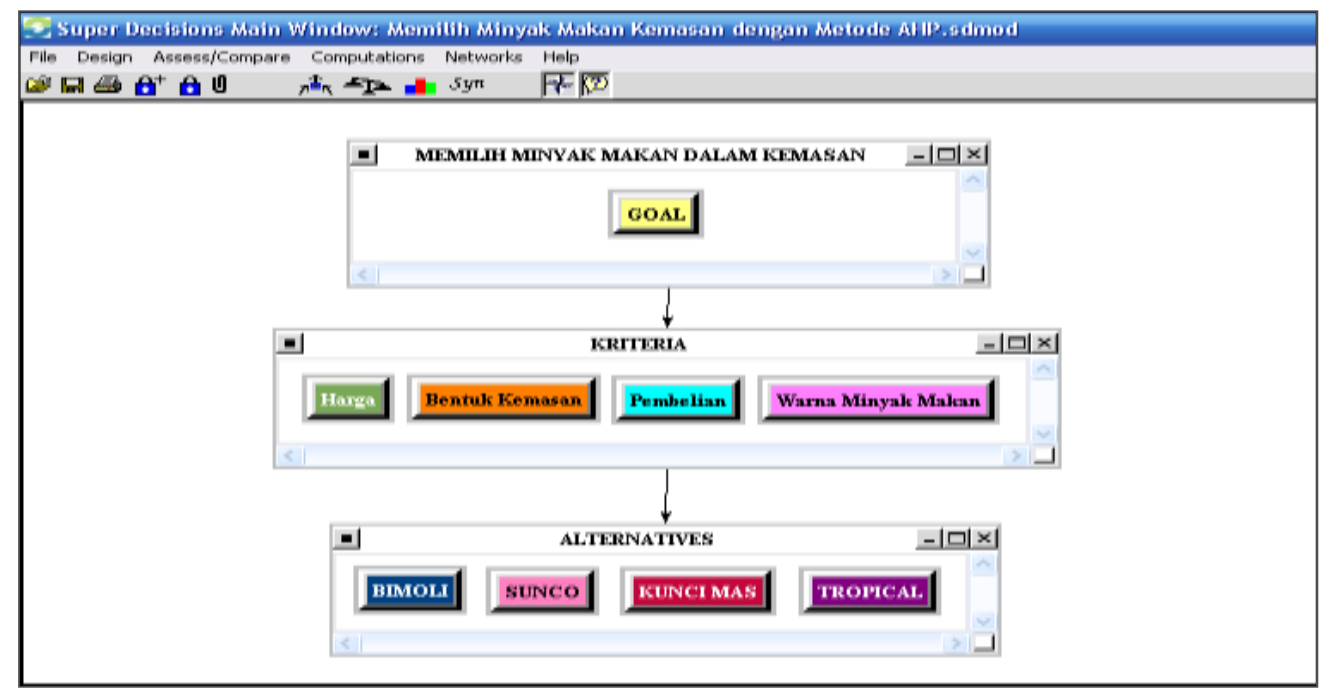

Gambar 2 Pembuatan Node 
Node yang ada dalam cluster kriteria dengan node-node dihubungkan dalam cluster Alternatives, diklik node harga, pilih node connexions form, ok kan dan lihat hasilnya di gambar 3

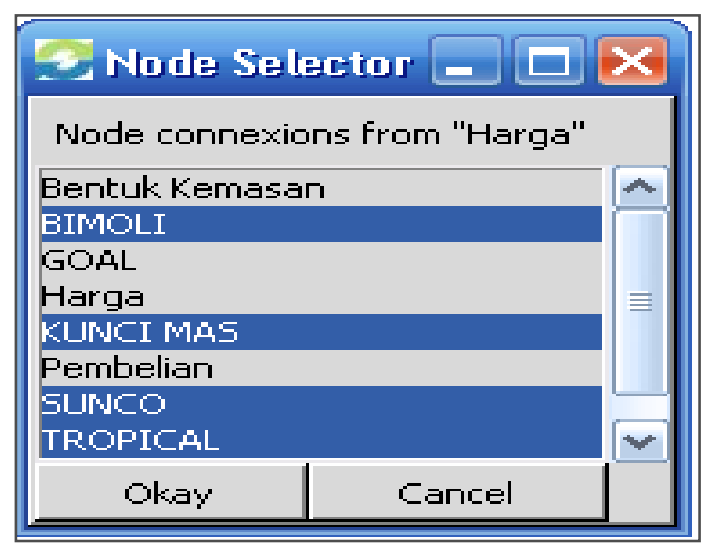

Gambar 3 Penggabungan antara Cluster

Semua cluster akan dikoneksikan dimana Alternativenya terdiri dari Minyak Makan Kemasan Bimoli, Sunco,Kunci Mas, dan Tropical akan saling terhubung dengan cluster kriteria yang terdiri dari harga, bentuk kemasan, pembelian dan warna minyak makanan. Semua nilai dari kuesioner dimasukkan dan setelah itu koneksikan di menu matrix yang bisadilihat digambar 4 dan 5

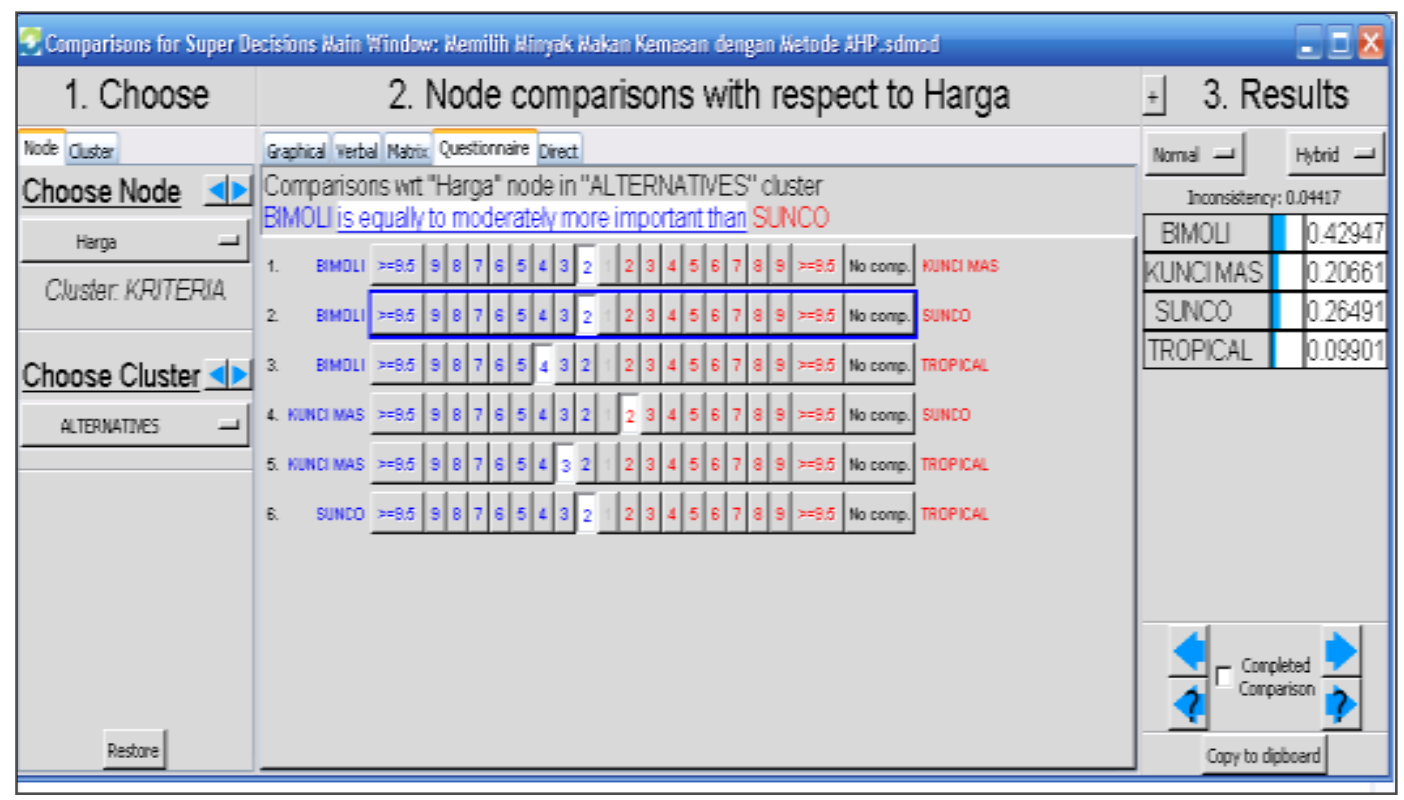

Gambar 4 Kuesioner Responden 


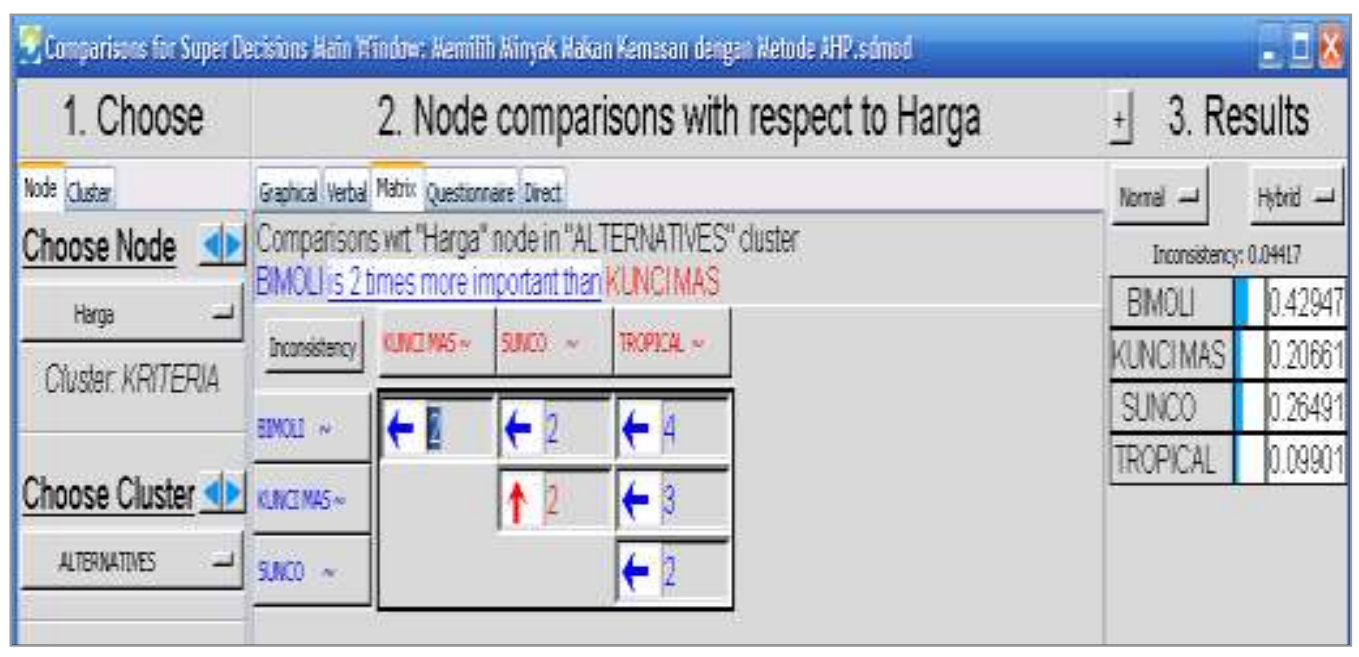

Gambar 5 Hasil Kuesioner

Untuk mendapatkan hasil dari consistency index dan prioritas tiap kriteria, langkahnya adalah dengan cara klik computations kemudian klik prioritas, dimana hasilnya seperti di gambar 6

\begin{tabular}{|c|c|c|c|c|}
\hline \multicolumn{5}{|c|}{ Here are the priorities. } \\
\hline Icon & Name & Normalized by Cluster & $\longdiv { \text { Limiting } }$ & $\widehat{\widehat{A}}$ \\
\hline No Icon & BIMOLI & $\longdiv { 0 . 2 9 4 8 7 }$ & $\longdiv { 0 . 1 4 7 4 3 4 }$ & \\
\hline No Icon & KUNCI MAS & 0.23915 & $\longdiv { 0 . 1 1 9 5 7 7 }$ & \\
\hline No Icon & SUNCO & 0.25373 & $\longdiv { 0 . 1 2 6 8 6 4 }$ & \\
\hline No Icon & TROPICAL & 0.21225 & $\longdiv { 0 . 1 0 6 1 2 6 }$ & \\
\hline No Icon & Bentuk Kemasan & 0.25000 & $\longdiv { 0 . 1 2 5 0 0 0 }$ & \\
\hline No Icon & Harga & 0.25000 & $\longdiv { 0 . 1 2 5 0 0 0 }$ & 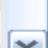 \\
\hline Okay $\mid \mathrm{Co}$ & py values & & & \\
\hline
\end{tabular}

Gambar 6 Hasil consistency index dan prioritas

Gambar 7 terlihat hasil akhir dari penelitian ini :

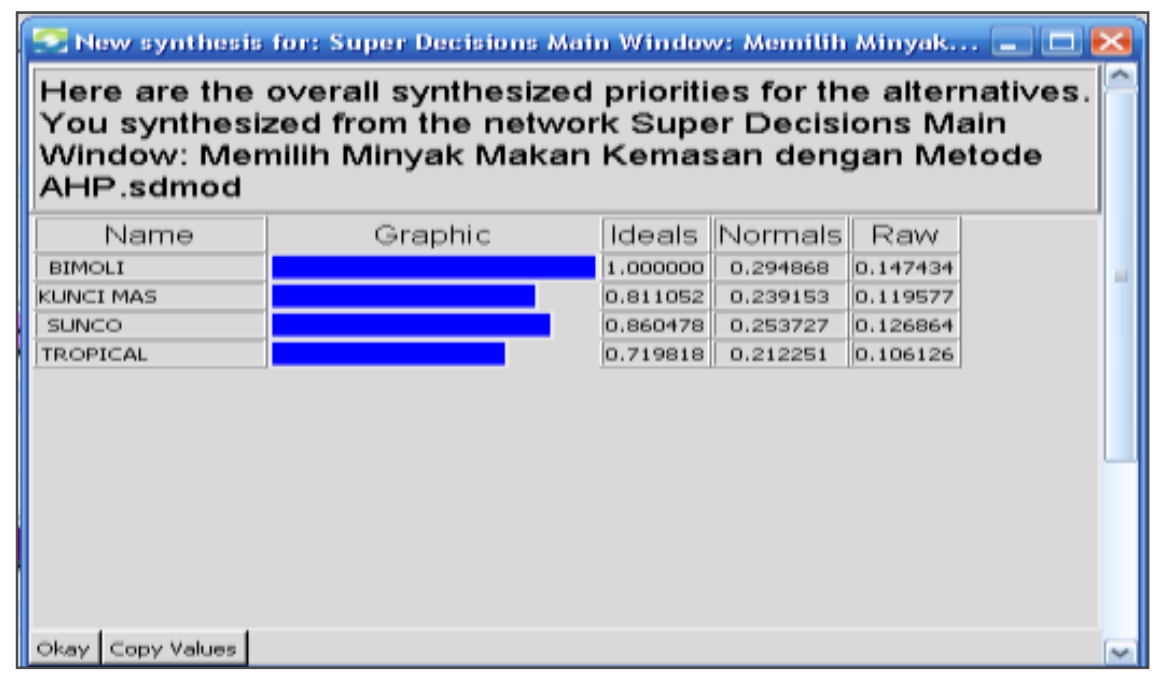

Gambar 7 Hasil Penelitian yang dilakukan 
Digambar 8 adalah hasil akhir yang yang dilakukan di superdecision.

\section{Report for toplevel}

This is a report for how alternatives fed up through the system to give us our synthesized values. Return to main menu

\section{Alternative Rankings}

\begin{tabular}{||c||c|c|c||c|c||}
\hline \multicolumn{1}{|c|}{ Graphic } & Alternatives & Total & Normal & Ideal & Ranking \\
\hline$\square$ & BDMOLI & 0.1474 & 0.2949 & 1.0000 & 1 \\
\hline \hline & KUNCI MAS & 0.1196 & 0.2392 & 0.8111 & 3 \\
\hline \hline & SUNCO & 0.1269 & 0.2537 & 0.8605 & 2 \\
\hline & TROPICAL & 0.1061 & 0.2123 & 0.7198 & 4 \\
\hline
\end{tabular}

Gambar 8 Hasil Rangking Minyak Makan Kemasan

\subsection{Hasil Akhir di Superdecision}

Hasil akhir dengan mempergunakan superdecision maka akan diperoleh hasilnya yaitu:

Tabel 4 Hasil Akhir Memilih Minyak Makan Kemasan

\begin{tabular}{|c|c|c|}
\hline $\begin{array}{l}\text { Nama Minyak } \\
\text { Makan Kemasan }\end{array}$ & Nilai Eigen Vektor & Rangking \\
\hline Bimoli & $\mathbf{0 . 2 9 4 9}$ & 1 \\
\hline Sunco & $\mathbf{0 . 2 5 3 7}$ & 2 \\
\hline Kunci Mas & $\mathbf{0 . 2 3 9 2}$ & $\mathbf{3}$ \\
\hline Tropical & $\mathbf{0 . 2 1 2 3}$ & 4 \\
\hline
\end{tabular}

Tabel 4 diatas hasil yang didapat dari responden, dimana Bimoli mendapatkan prosentasi $30 \%$, Sunco $25 \%$, Kunci Mas $24 \%$ dan Tropical $21 \%$.

\section{KESIMPULAN}

Penelitian ini dapat disimpulkan sebagai berikut:

1. Metode ini akan mempermudah Masyarakat untuk menentukan jenis Minyak Makan Kemasan yang paling baik.

2. Dalam penelitian ini mempunyai 4 Alternatif yaitu Minyak Makan Kemasan Bimoli, Sunco, Kunci Mas, dan Tropical dimana kriteria yaitu harga, bentuk kemasan, pembelian dan warna kemasan minyak.

3. Sofware yang dipergunakan dalam membantu proses metode AHP ini menggunakan Tools Superdesicion, dimana hasilnya sangat akurat untuk memperoleh hasil yang diinginkan oleh Masyarakat.

4. Kuisioner yang diberikan kepada 5 orang masyarakat dimana hasilnya didapat bahwa konsistensi dibawah 0,1 atau dibawah $10 \%$.

5. Penelitian ini membuktikan bahwa Minyak Makan Kemasan Bimoli adalah yang menjadi pilihan Masyarakat dalam memilih Minyak Makan Kemasan Terbaik. 


\section{SARAN}

Saran yang dapat diberikan yaitu :

1. Kedepannya dibuat metode lain sebagai perbandingan.

2. Metode ini bisa menjadi referensi bagi peneliti lainnya dan juga konsumen yang akan membutuhkannya dalam hal memilih produk minyak makan kemasan terbaik yang baik untuk kesehatan serta berkwalitas.

3. Bagi peneliti yang membutuhkan pengelolaan suatu data yang cukup besar, maka disarankan menggunakan perangkat lunak sistem pendukung keputusan lainnya yang bisa diimplementasikan sesuai dengan data yang cukup besar tersebut.

\section{DAFTAR PUSTAKA}

[1]. Faisal,et.al, 2015, “ Sistem Penunjang Keputusan Pemilihan Sekolah Menengah Kejuruan Teknik Komputer Dan Jaringan Yang Terfavorit Dengan Menggunakan Multi -Criteria Decision Making” , Jurnal Teknologi Informasi dan Ilmu Komputer Volume. 2 No.1.

[2]. Adhy P. , 2015, “ 'Sistem Pendukung Keputusan Pemilihan Pejabat Kopertis Wilayah III Menggunakan Metode Analytic Hierarchy Process (AHP) “ , Jurnal Penelitian Humaniora Volume. 20, 18-29.

[3]. Robby,et.al , 2015, “ Implementasi Metode AHP dan WP Dalam Sistem Pendukung Keputusan Pemilihan Susu Formula Balita”, Jurnal Ilmiah Go Infotech, Volume. 21 No.2, Desember 2015.

[4]. R.A Destari, 2016, “ Sistem Rangking Pemanfaatan Susu Bayi Menggunakan Analytical Network Process (ANP)" Vol. 6 No. 1, Sisfotenika

[5]. Sri .W, 2015, “ Sistem Pendukung Keputusan Penentuan Dosen Pembimbing Kerja Praktek dengan Metode Analytical Hierarchy Process Model Rating “, Vol. 7 No. 01 Media Jurnal Informatika

[6]. A.H Azhar, et.al, 2017, “ Improvement Accuracy Of Oil Meal Packaging With Method ANP ", International Conference on Cyber and IT Service Management (CITSM).

[7]. R. A Destari, et.al, 2018, " Application of ANP Methods for Selecting the Best Bread Products “, 6th International Conference on Cyber and IT Service Management (CITSM).

[8]. A. H Azhar , et.al, 2018, “ Improvement Accuracy of Instant Noodle Product Selection Using Method ANP “, International Conference on Cyber and IT Service Management (CITSM) 